\title{
Audit Information System Using Cobit 5
}

\author{
Ahmad Sujana ${ }^{1 *}$, Nurcaweda Riztria Adinda ${ }^{2}$, Ninik Sri Lestari ${ }^{3}$, Hetty Fadriani ${ }^{4}$, Adrew \\ Ghea Mahardika ${ }^{5}$ \\ \{*ahmadsujanasttm@gmail.com $\}$
}

Sekolah Tinggi Teknologi Mandala, Bandung, Indonesia

\begin{abstract}
A good SIAKAD is to provide good service to students, therefore it is not necessary to audit the academic information system which is one of the most important supports in a university, the existence of problems in the academic information system is very disturbing, both in service or in performance, as one example of printing KRS that is different from KHS, Sometimes there are differences in values between the values that exist in the system and KHS students, so there is a need for audits, whether from the security system or from user errors or users in running the system. Using Cobit version 5 is expected to be able to correct deficiencies in a system through the use of some parts of the domain in Cobit 5, in Cobit 5 there are several frameworks and Framework used, namely PAM (Process assessment model) with two domain processes, then DSS (Domain Support system) and MEA (Monitoring Evaluation and assess) with nine processes. From the results of audits conducted, measured from the ability level achieved, measurements obtained with the following data are the academic information systems in Mandala reaching 1.33. in other words that the academic information system currently exists at level 1 or Performing, and has a Gap of Capability Level that is expected to have a capability of 1.67 .
\end{abstract}

Keywords : Information, Academic, Students, COBIT, Information System

\section{Introduction}

Academic information systems are very important in an organization or information management, currently viewed as an asset for the company, its position is equal to other assets. Therefore there needs to be good management of the information system. One of the most important supports in a PT (Higher Education) as an education provider is a good academic service system so that the target for academic servants is achieved according to expectations. The management of the SIAKAD of the Mandala College of Technology has been carried out, but it has not been managed using structured approaches and methods, so it is not easy to measure the role of the SIAKAD in achieving the vision, mission determined by the STT Mandala. There are several definitions of information systems. [1] Information systems are a series of formal procedures in which data is grouped, information can be processed, and then distributed to users. [2] Management of Higher Education Academic Information Systems Based on Technology and Information and Communication.

\section{System Information audit stage}


Usually, a system effectiveness audit is carried out after a system has run for some time. [3] The Information Systems Audit and Control Association is a nonprofit organization that develops Information Systems standards and educational content. According to Solikin in his Paper [4] Information Systems Audit Model in Higher Education Using the Cobit Framework" from Ron Weber, there are 5 (five) steps or stages of an information system audit namely:

\subsection{Planing The audit}

Planning is the first phase of the audit activity, for external auditors this means to conduct an investigation of the client to find out whether auditing work is acceptable, place audit staff, produce audit agreements, produce client background information, understand client's legal issues and conduct analysis of existing procedures for understanding client's business and identifying audit risks

\subsection{Test Of control}

Auditors conduct test controls when they assess that risk control is at a level less than the maximum, they rely on control as a basis to reduce testing costs. Until this phase the auditor does not know whether the identification of controls has been carried out effectively, therefore a specific evaluation is needed.

\subsection{Test Of the transaction}

The auditor uses a test of transactions to evaluate whether errors or unusual processes occur in transactions that result in material recording errors in the financial statements. This transaction test includes tracing the journal from the source document, checking files and checking accuracy.

\subsection{Tests Of Balances or Overal Result}

To find out the approach used in this phase, which must be considered is the observation of property and data unity. Some types of substantive tests used are confirmation of accounts receivable, physical inventory calculations and recalculation of fixed assets.

\subsection{Completion Of The Audit}

In the final phase of the audit, the external audit will run several additional tests of the evidence to make it a report.

\section{Cobit 5}

in this case, COBIT 5 shows some clear differences where management, governance will reveal a holistic that can be seen the effects on the company from the scope of IT and the company may be more effective in managing governance assets. To achieve user satisfaction in its business, and to achieve business objectives, CoBit 5 has provided several guidelines for referencing the process that is very easy and detailed and very easy to access, in this case, CoBit combines some previous ISACA research.[5] Cobit 5 is based on 5 key corporate IT management and management principles as shown below: 


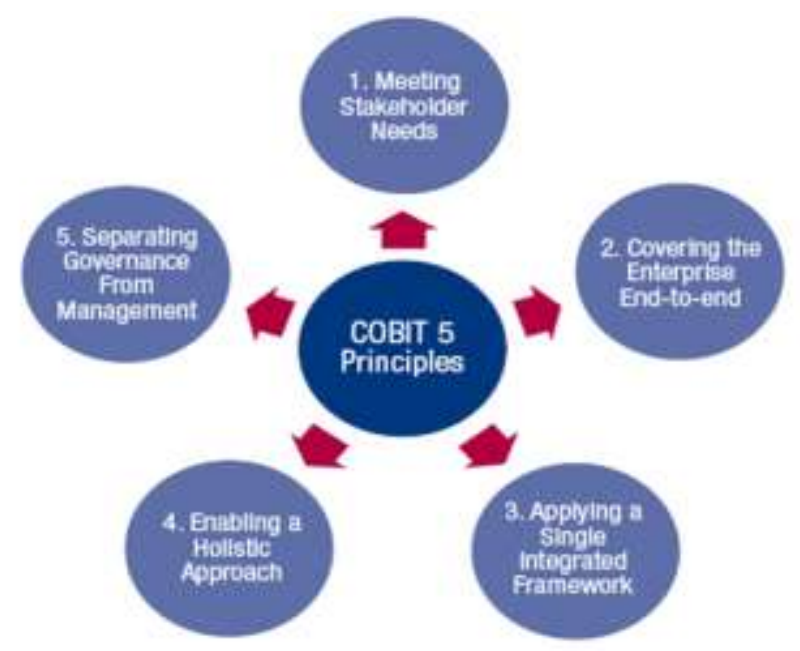

Fig.1. Cobit Framework

[6] Then COBIT 5 also describes 7 categories that act as movers as shown below

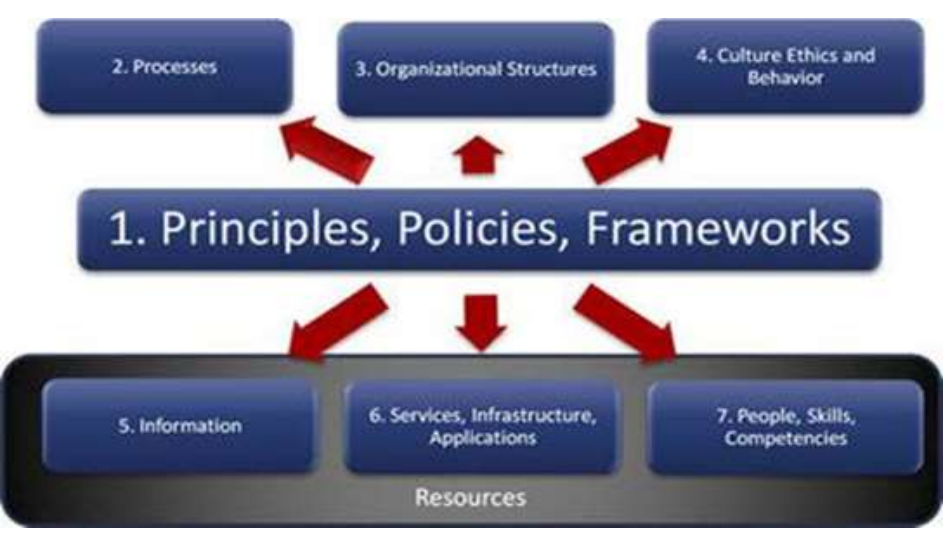

Fig. 2. Enabler

[7] The process assessment model (PAM) consists of two process dimensions in capability. The first process is defining the process and the second is clarifying into process categories, where each attribute will be grouped into several predetermined capability levels and provides measurable characteristics in the process capability. The PRM ( Process Reference Model) consists of 37 processes that describe the life cycle for corporate governance and IT management, as shown below: 


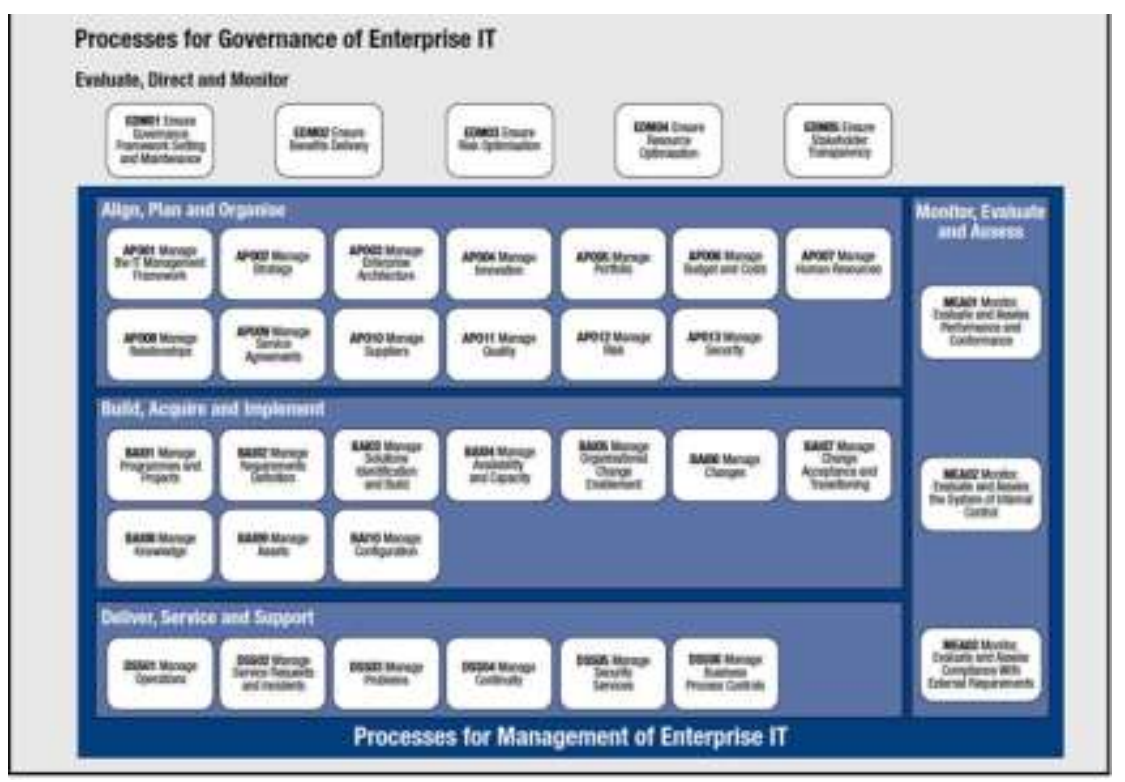

Fig.3. Reference Model Process

[8] Process Capability is stated in the process attributes are grouped into capability level, the process capability level is determined based on the achievement of certain processes by ISO / IEC 15504-2: 2003

Table 1. Capability levels and Process Atribut

\begin{tabular}{ll}
\hline Process Atribut ID & Capability Levels and Process Attributes \\
\hline & Level 0: informed Process \\
& Level 1: Performed Process \\
PA 1.1 & Process Performance \\
& Level 2: Managed Process \\
PA 2.1 & Performance Management \\
PA 2.2 & Work Product management \\
& Level 3: Esthabilished process \\
PA 3.1 & Process definition \\
PA 3.2 & Process deployment \\
& Level 4: Predictable process \\
PA 4.1 & Process Measurement \\
PA 4.2 & Process Control \\
& Level 5 Optimizing Process \\
PA 5.1 & Process Inovation \\
PA 5.2 & Process Optimization \\
\hline
\end{tabular}

in the latest ICASA Guidelines, how to discuss IT governance and management. CoBit 5 is made from some experience in using CoBit, More than 15 years many companies and users from the business sector, IT community, risk, insurance, and security. The CoBit 5 domain consists of several parts: 


\subsection{Evaluate, Direct and Monitor (EDM)}

This governance process deals with stakeholder agreements, risk optimization and resource optimization including practices and activities aimed at evaluating preferred strategies, providing guidance to IT and monitoring results.

\subsection{Align, Plan and Organise (APO)}

Provide direction for delivery solutions (BAI) and the provision of services and support (DSS). in the following domains discuss the scope of strategies, focus and tactics to identify how to make it in IT, can contribute to business achievement. needs to be realized from a strategic vision, the existence of communication to be managed from different perspectives. in an organization putting and having good infrastructure is needed.

\subsection{Build, Acquire and Implement, (BAI)}

having a solution in service change can realize IT strategies, the need to obtain IT identification and development, as well as implementation and integration in managing business processes. This domain also discusses maintenance and changes in the system so that it can meet and ensure the objectives of the business.

\subsection{Deliver, Service and Support (DSS)}

In this domain discussed the relationship in terms of actual delivery to support the services needed, which consists of security that is managed continuously and support for users of data management in the operational facility system

\subsection{Monitor, Evaluate and Assess (MEA)}

This domain addresses monitors in all processes aimed at ensuring that the available guidelines are followed. the interrelation of the IT process needs to be assessed all the time in terms of quality and follows the rules in the requirements. Also, it discusses performance management, monitoring internal control and following all governance regulations.

\section{Method}

To achieve the goals that have been determined, it needs the steps in solving the problem, the sequence of steps or research methods that are made systematically and logically so that it can be made clear and easy guidelines in solving problems. Based on the problems examined and the objectives to be achieved for this research, systematic research is determined in general which can be seen in figure 1 . 


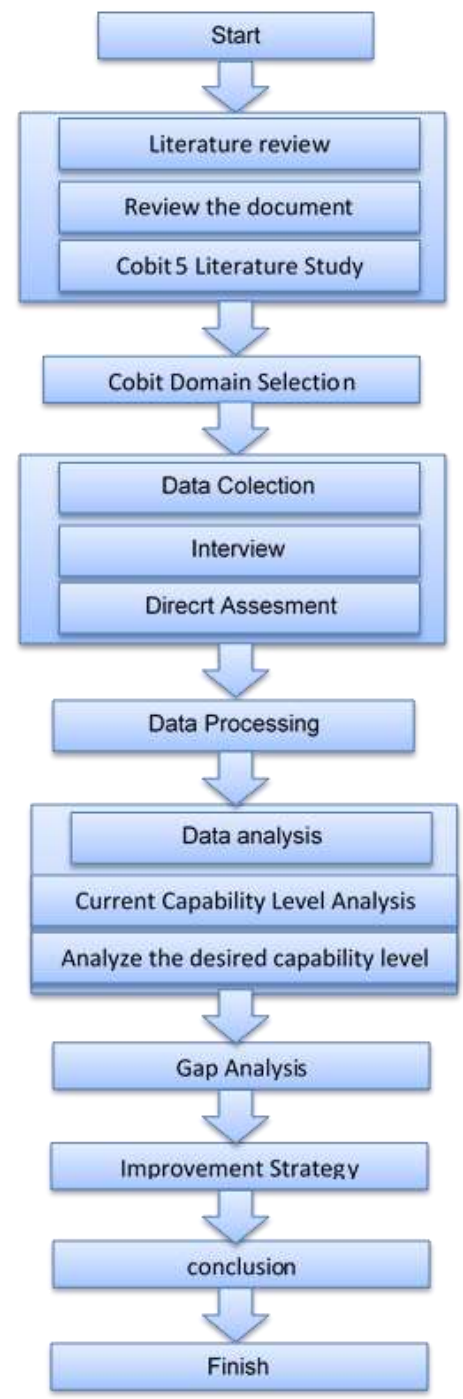

Fig.4. Research Flow

\section{Capability Level Assessment Process}

Based on the mapping of the COBIT process using the DSS and MEA Domains, there are 9 COBIT processes that will be measured its Capability Level. In assessing the capability level in COBIT process, each process is checked in stages whether the process has fulfilled the requirements that must be met at each level, starting from level 1 to level 5. In addition, there are category provisions from the results of the assessment at each level, that is, a process is sufficient to achieve the Largely achieved (L) category with a range of values ranging from $50-85 \%$ or Fully achieved $(\mathrm{F})$ with a range of values ranging from $85 \%-100 \%$ to be able to 
state that the process has achieved a level of capability., but the process must reach the Fully achieved (F) category to be able to continue the assessment to the next capability level.

\section{Capability Level Calculation Results}

From the results of an audit of the in (SIKAD) of STT Mandala Bandung that has been carried out, the capability level of the system is obtained. Where the target capability level for the entire process in the STT Mandala Bandung Academic Information System is 3.00 or at level 3 (Established).

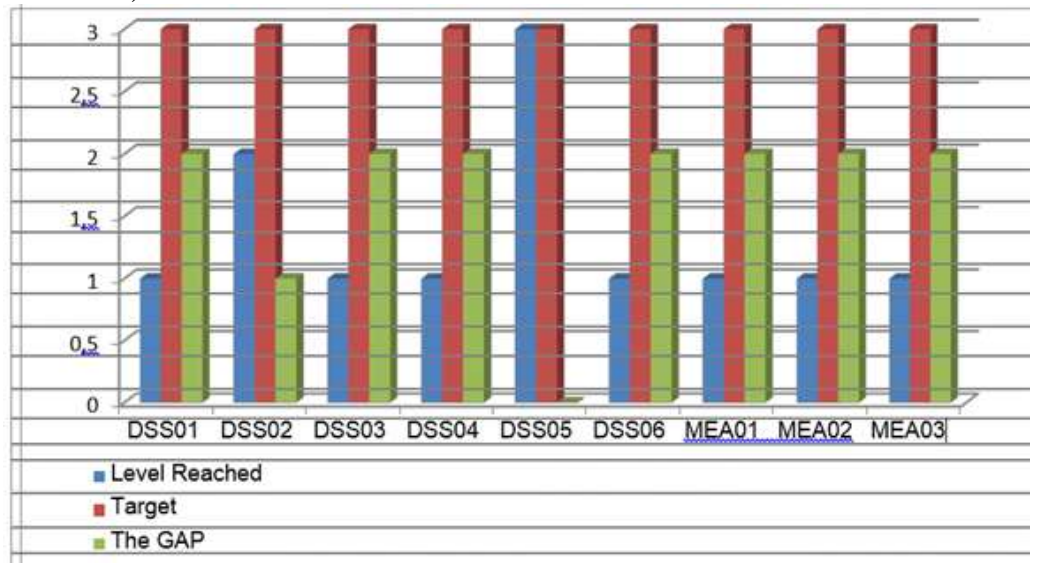

Fig.5. Graph of Capability Level Achievement of COBIT Process

In Figure 2. from the results of audits that have been carried out through 9 processes consisting of DSS and MEA domains in SIKAD Mandala there is one process that reaches level 3 or in other words established, which is contained in the DSS-05 process that is Manage Security Service. one process can reach level two or in other words managed contained in DSS-02 manage service requests and incident. other than that there is only level one which consists of DSS-01 Manage operation, DSS-03 Manage Problem, DSS-04 Manage Continuity, DSS06 manage business process controls and MEA-01, MEA-02, ME-A03 processes.

Of the Capability Level assessment obtained from the audit of the Mandala academic information system (SIKAD) which has a value of 1.33. so it can be concluded that SIKAD Mandala at the time of measurement or when audited at level 1 or still in the performed stage, then still has a Gap between capability level which is expected with the capability measurement results obtained, namely only 1.67.

\section{Conclusions}

In the Mandala academic system (SIKAD) by conducting a system audit using CoBit 5, the calculation results obtained by an average that only reached level 1 (performed) and there is a gap between the desired Capability level with the achievement level capability when measured only reached 1.67. Measurement of the capability level of the SIKAD process at Mandala using the COBIT 5 out of 9 processes, the capability level is obtained at this time 
there are no processes at level 0 , there are 7 processes at level 1,1 process at level 2 and 1 processes that are at level 3. SIKAD Mandala is still categorized as not good based on the evaluation results that are by the targets they have set at this time, namely level 3.

\section{References}

[1] Kadir Abdul, PengantarSistemInformasi, Jogjakarta, Andi Offset, 2003

[2] Indrayani Entin, Pengelolaan system Informasi Akademi perguruan Tinggi Berbasis Teknologi Informasi dan Komunikasi, Jurnal Penelitian Pendidikan,Vol. 12, No. 1, April 2011

[3] Angelique Dawkins, in Information system audit and control association Certification, 2019

[4] Solikin, Model Audit Sistem Informasi di Perguruan Tinggi dengan Menggunakan Kerangka CobIT, Paper 2004, STMIK AMIK Bandung

[5] ISACA. (2012). COBIT 5 A Business Framework for the Governance and Management of Enterprise IT. USA: ISACA

[6] ISACA, (2012).COBIT 5 Enabling Processes. USA: ISACA

[7] ISACA, (2012).COBIT 5 Implementation. USA: ISACA

[8] ISACA, (2013). PAM (Proses Asesment Model). USA: ISACA 